\title{
Gene microarray analysis of IncRNA and mRNA expression profiles in patients with high-grade ovarian serous cancer
}

\author{
YANHUI LOU, HUANHUAN JIANG, ZHUMEI CUI, XIANGYU WANG, LINGZHI WANG and YI HAN \\ Department of Gynecology, Affiliated Hospital of Qingdao University, Qingdao, Shandong 266100, P.R. China
}

Received June 23, 2017; Accepted March 16, 2018

DOI: $10.3892 / \mathrm{ijmm} .2018 .3588$

\begin{abstract}
High-grade ovarian serous cancer is known for its high rates of invasion and metastasis, and resultant high mortality rate. Therefore, research concerning biomarkers and underlying molecular mechanisms of high-grade ovarian serous cancer progression and prognosis are urgently required. Long non-coding RNAs (lncRNAs) have been the subject of an increasing number of studies, and certain lncRNAs have been demonstrated to serve an important function in the development and progression of various cancers, including HOX transcript antisense RNA, competing endogenous lncRNA 2 for microRNA let-7b, urothelial cancer associated 1, and H19, imprinted maternally expressed transcript (non-protein coding). However, few studies have investigated the differential expression of lncRNAs in high-grade ovarian serous cancer. In the present study, differences in lncRNA and mRNA expression profiles between high-grade ovarian serous cancer tissue samples and healthy fallopian tube tissue samples were investigated using microarray analysis, and the differential expression of IncRNAs and mRNAs was confirmed by reverse transcription-quantitative polymerase chain reaction (RT-qPCR). Then, five abnormally expressed lncRNAs were selected, and the associations between these lncRNAs and ovarian cancer clinicopathological parameters were examined using RT-qPCR. The expression profiles of certain lncRNAs and mRNAs were confirmed to be altered between high-grade ovarian serous cancer tissues and healthy fallopian tube tissues. Furthermore, the expression levels of selected lncRNAs were associated with International Federation of Gynecology and Obstetrics stage and lymph node metastasis. These lncRNAs and mRNAs may therefore be involved in the pathogenesis of high-grade ovarian serous cancer. The results of the present
\end{abstract}

Correspondence to: Dr Yanhui Lou, Department of Gynecology, Affiliated Hospital of Qingdao University, 59 Haier Road, Qingdao, Shandong 266100, P.R. China

E-mail: lyh7497@163.com

\section{Abbreviations: lncRNA, long non-coding RNA}

Key words: expression profile, high-grade ovarian serous cancer, long non-coding RNA, mRNA, microarray study provide an experimental foundation for further exploration of the value of these lncRNAs and mRNAs in the early diagnosis and treatment of high-grade ovarian serous cancer.

\section{Introduction}

Ovarian cancer has the highest mortality rate of all gynecologic malignancies (1). The disease is split into a number of classifications, including epithelial ovarian cancer, which accounts for $85-90 \%$ of malignant ovarian tumors (1). High-grade ovarian serous cancer is an aggressive type of epithelial ovarian cancer, with a high degree of malignancy and rapid progression. Compared with early-stage, high-grade ovarian serous cancer, the prognosis of patients with advanced high-grade ovarian serous cancer is poor, and the 5-year survival rate for these patients is only $27 \%$ (2). Adjacent organ invasion, multiple peritoneal implantation metastasis and lymph node metastasis are also observed in the majority of patients with advanced high-grade ovarian serous cancer (3). Therefore, studies investigating high-grade ovarian serous cancer development, progression-associated genes and regulatory mechanisms are necessary. Through these studies, researchers hope to improve our understanding of high-grade ovarian serous cancer progression and development, and identify long-term and effective treatment strategies for this disease.

The development of biological chips and high-throughput sequencing technology has revealed that it is possible to transcribe $\sim 70-90 \%$ of the human genome to RNAs, but only $1-2 \%$ of RNAs are ultimately translated to proteins $(4,5)$. The vast majority of RNAs do not have a protein-encoding function. These RNAs were classified as 'non-coding RNAs', and were originally thought to be either noise or waste products of transcription. With further research, non-coding RNAs were demonstrated to participate in a variety of physiologic and pathologic processes and to serve an important function in cancer progression (6). Long non-coding RNAs (lncRNAs) are a type of non-coding RNA, transcribed from intergenic and intronic regions in the human genome by RNA polymerase II, ranging in length from $200 \mathrm{nt}$ to $100 \mathrm{~kb}$ and lacking significant protein-coding open reading frames (7). The reported biological functions of lncRNAs include DNA damage repair, epigenetic control, transcription regulation, pre- and post-translational regulation, control of the cell cycle, survival, migration, metabolism and differentiation, and even control 
of the apoptotic process (8-11). Furthermore, a number of lines of evidence link the dysregulation of lncRNAs to diverse human diseases, particularly cancer (12-16). The lncRNA research field is, therefore, very promising. However, studies concerning lncRNAs and their function and regulation mechanisms remain in their infancy, particularly those concerning high-grade ovarian serous cancer. At present, few lncRNAs have been reported as associated with high-grade ovarian serous cancer, including HOX transcript antisense RNA (HOTAIR), HOXA11 antisense RNA, competing endogenous lncRNA 2 for microRNA let-7b, maternally expressed 3 and urothelial cancer associated 1 (UCA1) (17-21). Furthermore, the differential expression profiles of IncRNAs between high-grade ovarian serous cancer and healthy fallopian tube tissues, and their functional significance, remain unclear. The aim of the present study was to explore the expression profiles of lncRNAs and their potential target genes in high-grade ovarian serous cancer tissues, and to analyze the associations between these lncRNAs and clinicopathological features of ovarian cancer. The results of the present study may represent evidence supporting the involvement of lncRNA expression levels in the progression of high-grade ovarian serous cancer, and establish a foundation for the development of potential diagnostic biomarkers and therapeutic targets for the treatment of high-grade ovarian serous cancer.

\section{Materials and methods}

Patients and tissue specimens. High-grade ovarian serous cancer tissue specimens were obtained from patients (average age, 55 years) who had undergone surgical treatment for ovarian cancer at the Affiliated Hospital of Qingdao University (Qingdao, China) between March 2015 and March 2016. Healthy fallopian tube tissue specimens were obtained from patients (average age, 53 years) who had undergone surgical treatment for hysteromyoma at the Affiliated Hospital of Qingdao University during the same period. All cases were confirmed by postoperative pathological diagnosis. Patients who had received neoadjuvant chemotherapy or radiation therapy prior to surgery were excluded from the present study. A total of 23 high-grade ovarian serous cancer tissue samples and 23 healthy fallopian tube tissue samples were collected. Of these samples, 3 high-grade ovarian serous cancer samples (labeled A1-3) and 3 healthy fallopian tube tissue samples (labeled B1-3) were used for global profiling of human IncRNA and mRNA expression using the Arraystar human lncRNA microarray (Arraystar, Inc., Rockville, MD, USA). A further 20 pairs of samples were used for confirmation of differential lncRNA and mRNA expression by reverse transcription-quantitative polymerase chain reaction (RT-qPCR) analysis. In addition, 40 high-grade ovarian serous cancer tissue samples were collected to analyze the associations between differential lncRNA expression and ovarian cancer clinicopathological parameters, using RT-qPCR analysis. These samples were obtained from patients (average age, 55 years) who had undergone surgical treatment for ovarian cancer at the Affiliated Hospital of Qingdao University between March 2016 and June 2017. All samples were stored at $-80^{\circ} \mathrm{C}$ immediately following surgical resection. All subjects provided signed statements of written informed consent, and all experimental procedures were approved by the Institutional Review Board of the Ethics Board of the Affiliated Hospital of Qingdao University.

RNA extraction and quality control. Total RNA was extracted from the tissue samples using TRIzol reagent (Invitrogen; Thermo Fisher Scientific, Inc., Waltham, MA, USA), according to the manufacturer's protocol. The entire process was performed on ice. The quantity and quality of the RNA samples were measured using a NanoDrop ND-1000 spectrophotometer. RNA integrity was assessed using standard $1 \%$ denaturing agarose gel electrophoresis. Isolated RNA was stored at $-80^{\circ} \mathrm{C}$ and prepared for lncRNA array analysis and RT-qPCR.

RNA labeling and array hybridization. Sample labeling and array hybridization were performed according to the Agilent one-color microarray-based gene expression analysis protocol (Agilent Technologies, Inc., Santa Clara, CA, USA) with minor modifications. Briefly, mRNA was purified from the total RNA following removal of rRNA (using an mRNA-ONLY ${ }^{\mathrm{TM}}$ Eukaryotic mRNA Isolation kit; Epicentre; Illumina, Inc., San Diego, CA, USA). Then, each sample was amplified and transcribed into fluorescent cRNA along the entire length of the transcripts without 3 ' bias, utilizing a random priming method (using a Arraystar Flash RNA 1 Labeling kit; Arraystar, Inc.). The labeled cRNA was purified using an RNeasy mini kit (Qiagen, Inc., Valencia, CA, USA). The concentration and specific activity of the labeled cRNAs (pmol Cy3/ $\mu \mathrm{g}$ cRNA) were measured using a NanoDrop ND-1000 spectrophotometer. An Agilent Gene Expression Hybridization kit (cat. no. 5188-5242) was purchased from Agilent Technologies, Inc. and each labeled cRNA $(1 \mu \mathrm{g})$ was fragmented by adding $5 \mu \mathrm{l} 10 \mathrm{X}$ blocking agent and $1 \mu \mathrm{l} 25 \mathrm{X}$ fragmentation buffer. The mixture was heated at $60^{\circ} \mathrm{C}$ for $30 \mathrm{~min}$. Finally, $25 \mu \mathrm{l}$ 2X GE Hybridization buffer was added to dilute the labeled cRNA. A total of $50 \mu \mathrm{l}$ hybridization solution was dispensed into the gasket slide and assembled to the lncRNA expression microarray slide. The slides were incubated for $17 \mathrm{~h}$ at $65^{\circ} \mathrm{C}$ in an Agilent hybridization oven (Agilent Technologies, Inc.). The hybridized arrays were washed, fixed, and scanned using the Agilent DNA microarray scanner (part no. G2505C; Agilent Technologies, Inc.).

Microarray data analysis. Agilent feature extraction software (version 11.0.1.1; Agilent Technologies, Inc.) was used to analyze the acquired array images. Quantile normalization and subsequent data processing were performed using the GeneSpring GX version 12.1 software package (Agilent Technologies, Inc.). Following quantile normalization of the raw data, IncRNAs and mRNAs, for which at least 3 out of 6 samples had flags in Present or Marginal ('All targets value') were selected for further data analysis. Differentially expressed lncRNAs and mRNAs with statistical significance between high-grade ovarian serous cancer and healthy fallopian tube tissue were identified through $\mathrm{P}$-value $(<0.05)$ and false discovery rate $(<0.1)$ filtering. Differentially expressed lncRNAs and mRNAs between the two samples were identified through fold change filtering. Pathway analysis and Gene Ontology (GO) analysis $(22,23)$ were applied to determine 
Table I. Primer sequences for lncRNAs and mRNAs.

\begin{tabular}{|c|c|c|}
\hline Gene name & Forward (5'-3') & Reverse (5'-3') \\
\hline GTSE1-AS1 & TCTTAAGCTTCCTGAGGTTGCAC & AGAGGTTTAATTGGCTCACAGTTC \\
\hline$F A S-A S 1$ & CAAAACAGGCTGCTCAAGTTTC & GGGTTGGTGGTACTCGTTCC \\
\hline AK130076 & TGGCCATCCCTACAGTGCTAG & TGGAGTGCAGTGGTGCGATC \\
\hline$R P 11-199 F 11.2$ & GTGCCTGTAATCCCAGCTATTC & TGAGACGGAGTTTCGTTCTTGTC \\
\hline AC093818.1 & CACTCACCGAAGTCCAGGAAC & GCAGCTTCAGCTCGGACTC \\
\hline GTSE1 & GATGACCCCCAAAACGATG & TTCTGTTGCTCTCCCTTGTTG \\
\hline FAS & ACACTCACCAGCAACACCAA & ТССТТТСТСТТСАСССАААСА \\
\hline PTEN & AGACCATAACCCACCACAGC & ACCAGTTCGTCCCTTTCCA \\
\hline TP53 & TAGTGTGGTGGTGCCCTATG & CCAGTGTGATGATGGTGAGG \\
\hline$P D K 1$ & GATGAGTGACCGAGGAGGTG & TAACCAAAACCAGCCAGAGG \\
\hline$G A P D H$ & CTCAGACACCATGGGGAAGGTGA & ATGATCTTGAGGCTGTTGTCATA \\
\hline
\end{tabular}

GTSE1-AS1, GTSE1 antisense RNA 1 (head to head); FAS-AS1, FAS antisense RNA 1; GTSE1, G2 and S-phase expressed 1; FAS, Fas cell surface death receptor; PTEN, phosphatase and tensin homolog; TP53, tumor protein p53; PDK1, pyruvate dehydrogenase kinase 1.

which pathways were affected by these differentially expressed lncRNAs and mRNAs. Hierarchical clustering and combined analysis were performed using in-house scripts.

RT-qPCR analysis of lncRNA and mRNA expression. Expression levels of lncRNAs and mRNAs were validated by RT-qPCR analysis among 20 high-grade ovarian serous cancer samples. Total RNA was extracted from the tissue samples using TRIzol reagent (Invitrogen; Thermo Fisher Scientific, Inc.). Total RNA was reverse-transcribed to cDNA using a TRUEscript 1st strand cDNA synthesis kit (Aidlab Biotechnologies Co., Ltd., Beijing, China) following the manufacturer's protocol. Reactions were incubated for $30 \mathrm{~min}$ at $42^{\circ} \mathrm{C}, 5 \mathrm{~min}$ at $85^{\circ} \mathrm{C}$, and then samples were stored at $-20^{\circ} \mathrm{C}$. qPCR was performed using $2 \mathrm{X}$ SYBR green $\mathrm{qPCR}$ mix (Aidlab Biotechnologies Co., Ltd.) in an ABI 7900HT sequence detection machine (Thermo Fisher Scientific, Inc.). The reactions were incubated at $95^{\circ} \mathrm{C}$ for $3 \mathrm{~min}$, followed by 40 cycles at $95^{\circ} \mathrm{C}$ for $15 \mathrm{sec}$ and at $60^{\circ} \mathrm{C}$ for $40 \mathrm{sec}$. Primer sequences for 5 lncRNAs and 5 mRNAs were designed and synthesized (Table I). GAPDH was used as an internal control. Target and reference (GAPDH) genes were amplified in separate wells and run in triplicate. Statistical analyses of the results were performed using the $2^{-\Delta \Delta \mathrm{Cq}}$ relative quantification method (24).

Statistical analysis. SPSS 17.0 (SPSS, Inc., Chicago, IL, USA) and GraphPad Prism 5.0 (GraphPad Software, Inc., La Jolla, CA, USA) were used for statistical analysis. Data are presented as the mean \pm standard deviation. The statistical significance of the microarray results was analyzed by fold change and Student's t-test. $\mathrm{P}<0.05$ was considered to indicate a statistically significant difference.

\section{Results}

RNA quality control. The integrity of RNAs was assessed by electrophoresis on a denaturing agarose gel. The $28 \mathrm{~S}$ and $18 \mathrm{~S}$ ribosomal RNA bands should appear as relatively sharp,

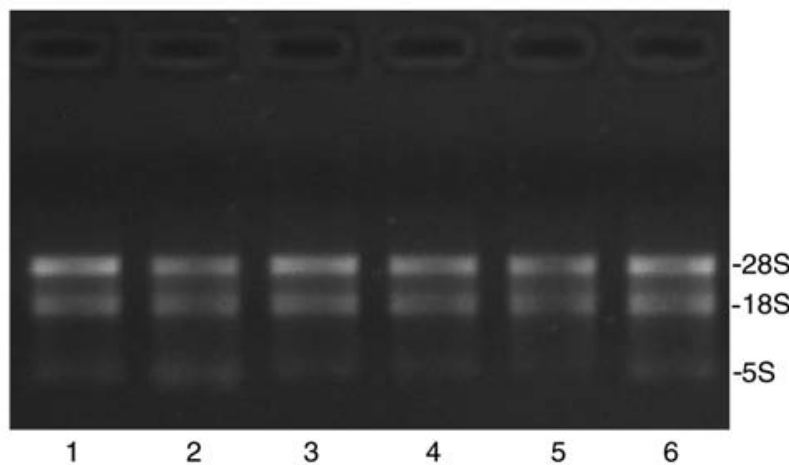

Figure 1. RNA integrity and gDNA contamination test by denaturing agarose gel electrophoresis. The $28 \mathrm{~S}$ and $18 \mathrm{~S}$ rRNA bands are clear and intact. Furthermore, the $28 \mathrm{~S}$ band is twice as intense as the $18 \mathrm{~S}$ band. Lanes 1-3 represent high-grade ovarian serous cancer tissue samples (A1-A3) while lanes 4-6 represent healthy fallopian tube tissue samples (B1-B3). gDNA, genomic DNA; rRNA, ribosomal RNA.

intense bands. The intensity of the upper band (28S rRNA band) should be $\sim 2 \mathrm{x}$ that of the lower band (18S rRNA band). Fig. 1 revealed that the total RNA obtained was of high purity. Total RNA quantification and quality were assured using the NanoDrop ND-1000 spectrophotometer. For spectrophotometry, the optical density A260/A280 ratio should be close to 2.0 for pure RNA (ratios between 1.8 and 2.1 are acceptable). The optical density A260/A230 ratio should be $>1.8$. In the present study, the total RNA quality of each sample was demonstrated (Table II), suggesting that the samples were appropriate for use in further experiments.

Overview of IncRNA and $m R N A$ profiles. The Arraystar human lncRNA microarray v. 4.0 is designed for the global expression profiling of human IncRNA and protein-coding mRNA transcripts. The array is able to detect a total of 40,173 lncRNAs and 20,730 protein-coding mRNAs. In the present study, 4,289 differentially expressed lncRNAs and 4,246 differentially expressed mRNAs were detected between high-grade ovarian 
Table II. RNA quantification and quality assurance, as assessed using a NanoDrop ND-1000 spectrophotometer.

\begin{tabular}{lcccccc}
\hline Sample ID & OD260/280 & OD260/230 & Concentration $(n g / \mu 1)$ & Volume $(\mu 1)$ & Quantity (ng) & QC result (pass or fail) \\
\hline A1 & 2.00 & 2.24 & $1,550.05$ & 80 & $124,004.0$ & Pass \\
A2 & 2.03 & 2.33 & $1,175.57$ & 80 & $94,045.6$ & Pass \\
A3 & 1.99 & 2.26 & 888.76 & 100 & $88,876.0$ & Pass \\
B1 & 1.97 & 2.27 & 594.67 & 40 & $23,786.8$ & Pass \\
B2 & 1.89 & 2.32 & 420.78 & 40 & $16,831.2$ & Pass \\
B3 & 1.89 & 2.36 & 357.84 & 40 & $14,313.6$ & Pass \\
\hline
\end{tabular}

A1-A3: high-grade ovarian serous cancer tissue samples; B1-B3: healthy fallopian tube tissue samples; OD, optical density; QC, quality control.

Table III. The 10 most upregulated and downregulated lncRNAs in high-grade ovarian serous cancer tissues compared with non-tumor tissues, compared by volcano plot.

A, Upregulated lncRNAs

\begin{tabular}{|c|c|c|c|c|c|}
\hline Seq. name & Gene symbol & Fold change & Chromosome & Associated gene name & Associated protein name \\
\hline TCONS_12_00000435 & XLOC_l2_000324 & 81.26 & chr1 & & \\
\hline NR_002947 & TCAM1P & 62.61 & $\operatorname{chr} 17$ & & \\
\hline NR_002712 & $C X C R 2 P 1$ & 45.67 & $\operatorname{chr} 2$ & & \\
\hline uc002ушу.3 & AK027145 & 43.38 & $\operatorname{chr} 21$ & KCNJ15 & $\begin{array}{l}\text { ATP-sensitive inward rectifier } \\
\text { potassium channel } 15\end{array}$ \\
\hline ENST00000419814 & $R P 11-131 J 3.1$ & 41.20 & chr1 & & \\
\hline NR_027072 & LINC00189 & 38.96 & $\operatorname{chr} 21$ & & \\
\hline ENST00000428667 & AP000695.4 & 36.94 & $\operatorname{chr} 21$ & CLDN14 & Claudin-14 \\
\hline ENST00000470135 & RP5-884M6.1 & 35.52 & $\operatorname{chr} 7$ & & \\
\hline ENST00000455309 & AC017002.1 & 27.37 & $\operatorname{chr} 2$ & & \\
\hline ENST00000606457 & $R P 11-1 C 8.7$ & 23.40 & chr8 & & \\
\hline
\end{tabular}

B, Downregulated lncRNAs

\begin{tabular}{|c|c|c|c|c|c|}
\hline Seq. name & Gene symbol & Fold change & Chromosome & Associated gene name & Associated protein name \\
\hline ENST00000556942 & $R P 11-356 K 23.1$ & 1221.26 & $\operatorname{chr} 14$ & FOXN3 & $\begin{array}{l}\text { Forkhead box protein N3 } \\
\text { isoform } 1\end{array}$ \\
\hline ENST00000556942 & $R P 11-356 K 23.1$ & 1221.26 & $\operatorname{chr} 14$ & $F O X N 3$ & $\begin{array}{l}\text { Forkhead box protein N3 } \\
\text { isoform } 2\end{array}$ \\
\hline uc031qjg.1 & $A K 129935$ & 845.63 & $\operatorname{chr} 12$ & & \\
\hline ENST00000574178 & $R P 11-424 M 24.5$ & 439.06 & chr16 & & \\
\hline ENST00000584807 & WI2-1959D15.1 & 331.26 & chr9 & CR392000.1 & $\begin{array}{l}\text { UniProtKB/TrEMBL or } \\
\text { E7EUX6 }\end{array}$ \\
\hline AL049990 & AL049990 & 330.93 & $\operatorname{chr} 4$ & & \\
\hline NR_110114 & LOC101927668 & 324.98 & $\operatorname{chr} 7$ & & \\
\hline NR_003063 & $T U B A 4 B$ & 302.06 & $\operatorname{chr} 2$ & & \\
\hline uc002xuq.1 & AK055386 & 239.29 & chr20 & & \\
\hline NR_110916 & LINC01571 & 221.41 & chr16 & & \\
\hline
\end{tabular}

LncRNA, long non-coding RNA.

serous cancer tissue samples and healthy fallopian tube tissue samples, using this fourth-generation IncRNA microarray (fold change, $\geq 2.0 ; \mathrm{P}<0.05$ ). Among these lncRNAs, 1,511 were upregulated and 2,778 were downregulated. The most upregulated lncRNA was TCONS_12_00000435 (fold change, 81.26) and the most downregulated lncRNA was RP11-356K23.1 (fold 
Table IV. The 10 most upregulated and downregulated mRNAs in high-grade ovarian serous cancer tissues compared with non-tumor tissues, compared by volcano plot.

A, Upregulated mRNAs

\begin{tabular}{llcll}
\hline Seq. name & Gene symbol & Fold change & Chromosome & \\
\hline NM_153426 & PITX2 & 333.42 & chr4 & Paired-like homeodomain 2 \\
NM_001884 & HAPLN1 & 184.94 & chr5 & Hyaluronan and proteoglycan link protein 1 \\
NM_002125 & HLA-DRB5 & 184.27 & chr6 & Major histocompatibility complex, class II, DR beta 5 \\
NM_021192 & HOXD11 & 119.74 & chr2 & Homeobox D11 \\
NM_014391 & ANKRD1 & 112.86 & chr10 & Ankyrin repeat domain 1 (cardiac muscle) \\
NM_003108 & SOX11 & 111.46 & chr2 & SRY-box 11 \\
NM_001854 & COL11A1 & 106.05 & chr1 & Collagen, type XI, alpha 1 \\
NM_003469 & SCG2 & 93.91 & chr2 & Secretogranin II \\
NM_005733 & KIF20A & 91.34 & chr5 & Kinesin family member 20A \\
NM_022346 & NCAPG & 74.57 & chr4 & Non-SMC condensin I complex subunit G \\
\hline
\end{tabular}

B, Downregulated mRNAs

\begin{tabular}{|c|c|c|c|c|}
\hline Seq. name & Gene symbol & Fold change & Chromosome & Description \\
\hline NM_176813 & $A G R 3$ & 2696.97 & $\operatorname{chr} 7$ & $\begin{array}{l}\text { Anterior gradient } 3 \text {, protein disulphide isomerase } \\
\text { family member }\end{array}$ \\
\hline NM_006408 & $A G R 2$ & 1914.59 & $\operatorname{chr} 7$ & $\begin{array}{l}\text { Anterior gradient } 2 \text {, protein disulphide isomerase } \\
\text { family member }\end{array}$ \\
\hline NM_053285 & TEKT1 & 1848.50 & $\operatorname{chr} 17$ & Tektin 1 \\
\hline NM_003357 & $S C G B 1 A 1$ & 1791.03 & $\operatorname{chr} 11$ & Secretoglobin family $1 \mathrm{~A}$ member 1 \\
\hline NM_031956 & TTC29 & 1334.47 & chr4 & Tetratricopeptide repeat domain 29 \\
\hline NM_001004303 & C1orf168 & 1088.35 & $\operatorname{chr} 1$ & Chromosome 1 open reading frame 168 \\
\hline NM_001080537 & SNTN & 1051.19 & $\operatorname{chr} 3$ & Sentan, cilia apical structure protein \\
\hline NM_000777 & CYP3A5 & 1007.52 & $\operatorname{chr} 7$ & Cytochrome P450 family 3 subfamily A member 5 \\
\hline NM_024730 & $R E R G L$ & 778.24 & $\operatorname{chr} 12$ & RERG/RAS-like \\
\hline NM_005634 & SOX3 & 752.28 & $\operatorname{chrX}$ & SRY-box 3 \\
\hline
\end{tabular}

change, 1221.26). In addition, 1,834 mRNAs were upregulated while 2,412 mRNAs were downregulated. The most upregulated mRNA was paired-like homeodomain 2 (fold change, 333.42) and the most downregulated mRNA was anterior gradient 3 (fold change, 2696.97). The 10 most upregulated and downregulated lncRNAs (Table III) and mRNAs (Table IV) were listed. Distinguishable lncRNA and mRNA expression patterns of the samples are presented via heat maps of the hierarchical clustering (Fig. 2A and B). Reproducible changes in gene expression were observed between the two groups through scatter plots (Fig. 3A and B). LncRNAs and mRNAs with statistically significant differences in expression between the two groups (fold change, $\geq 2.0 ; \mathrm{P}<0.05$ ) were identified by volcano plot filtering (Fig. 4A and B).

Bioinformatics analysis. Pathway analysis was used to determine biological pathways where differentially expressed genes were significantly enriched, according to the Kyoto Encyclopedia of Genes and Genomes (25), BioCarta (26) and Reactome (27,28) databases (29). Total pathway analysis results revealed that 121 pathways had significant differences in gene expression between high-grade ovarian serous cancer tissue samples and healthy fallopian tube tissue samples. Of these, 61 pathways were upregulated and 60 were downregulated. The top ten upregulated and downregulated pathways are presented in Fig. 5A and B. The top three upregulated pathways included systemic lupus erythematosus, alcoholism and viral carcinogenesis. The top three downregulated pathways included drug metabolism-cytochrome P450, cGMP-PKG signaling pathway, and chemical carcinogenesis.

GO analysis was used to analyze the main functions of the differentially expressed genes, according to the GO database. The GO database provides the key functional classifications for the National Center for Biotechnology Information (22), which comprises three structured networks: Biological processes, cellular components and molecular function (30). The most enriched GO terms in each structured network were mitotic cell cycle, chromosome, protein binding, cilium organization, cilium, and calcium ion binding. The first three of these terms were associated with upregulated genes in high-grade ovarian serous cancer tissue samples compared with the healthy 

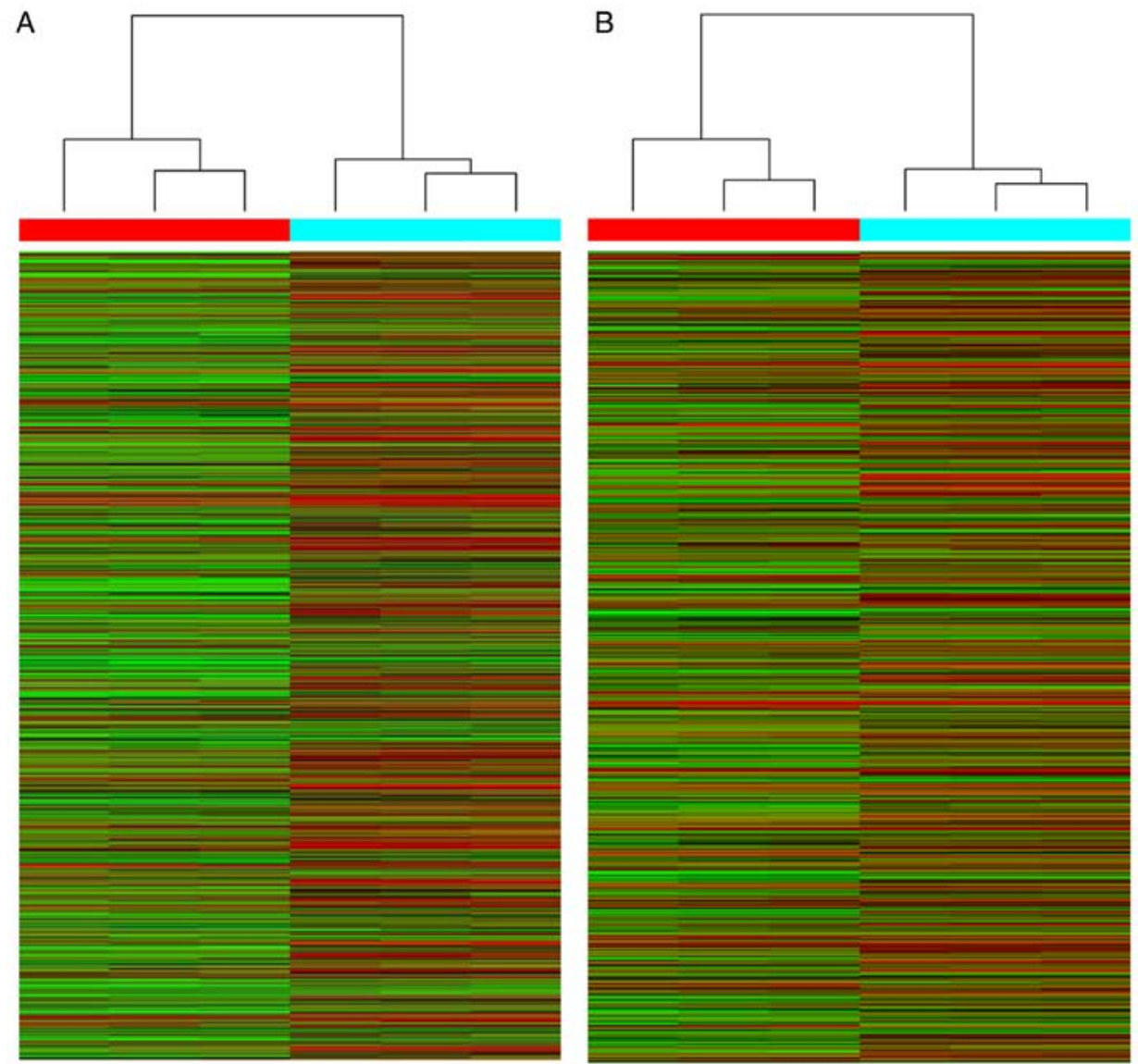

$\begin{array}{llllll}\text { A1 } & \text { A2 } & \text { A3 } & \text { B1 } & \text { B2 } & \text { B3 }\end{array}$

$\mathrm{A} 1$

A2

B1

B2

B3

Figure 2. Heat map and hierarchical clustering. Cluster analysis arranges samples into groups based on their expression levels. This analysis was performed to examine distinguishable (A) long non-coding RNA and (B) mRNA expression patterns among the samples. In the dendrogram, red indicates high relative expression and green indicates low relative expression. A1-A3 represent high-grade ovarian serous cancer tissue samples. B1-B3 represent healthy fallopian tube tissue samples.
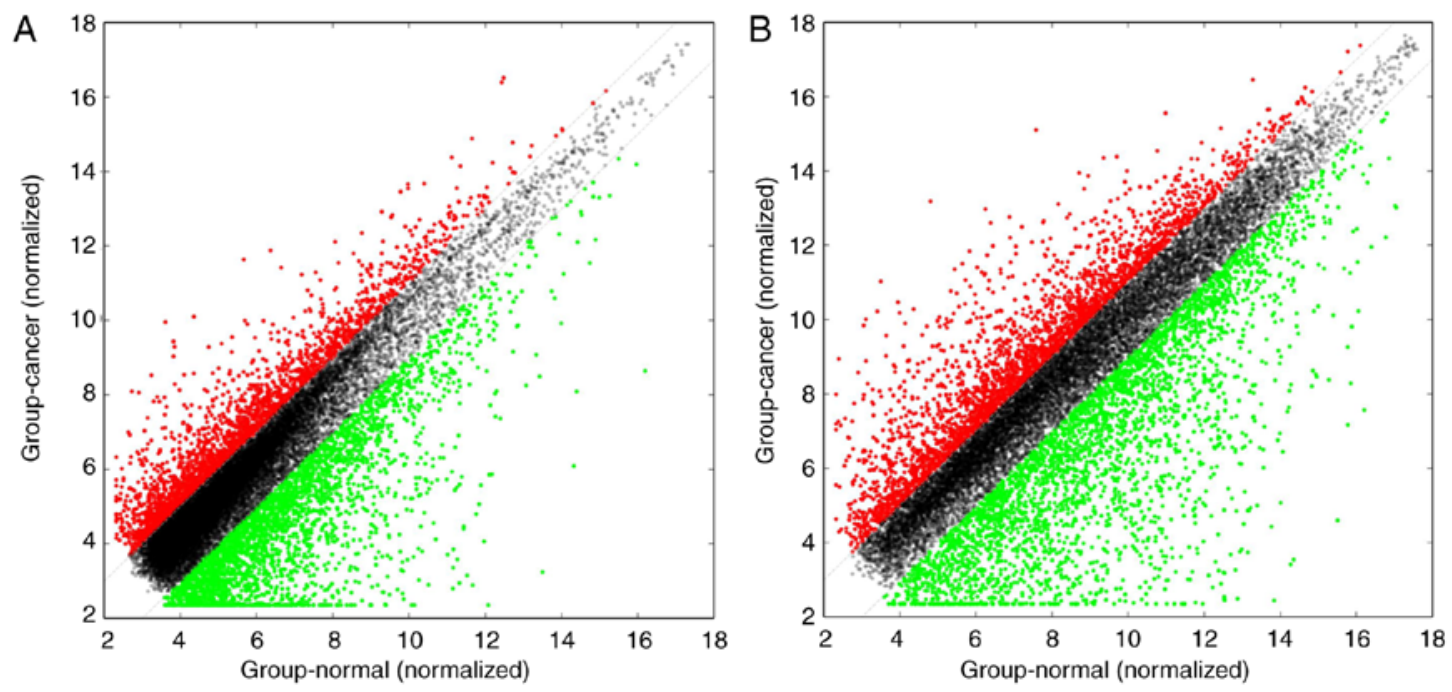

Figure 3. Scatter plots were used to assess variation in (A) long non-coding RNA and (B) mRNA expression between the two groups. The values plotted on the $\mathrm{X}$ and $\mathrm{Y}$ axes are the averaged normalized signal values in each group ( $\log 2$ scaled). Red points in the plot indicate $>2.0$-fold upregulation of expression between the two groups, green points indicate $>2.0$-fold downregulation of expression, and black points indicate $<2.0$-fold change in expression.

fallopian tube tissue samples, and the last three terms were associated with downregulated genes. The top ten upregulated and downregulated GO functions of score enrichment terms are presented in Fig. 6.
Subgroup analysis. Subgroup analysis was used to further investigate the associations between IncRNA expression and high-grade ovarian serous cancer. The differentially expressed antisense IncRNAs and their associated mRNAs were 

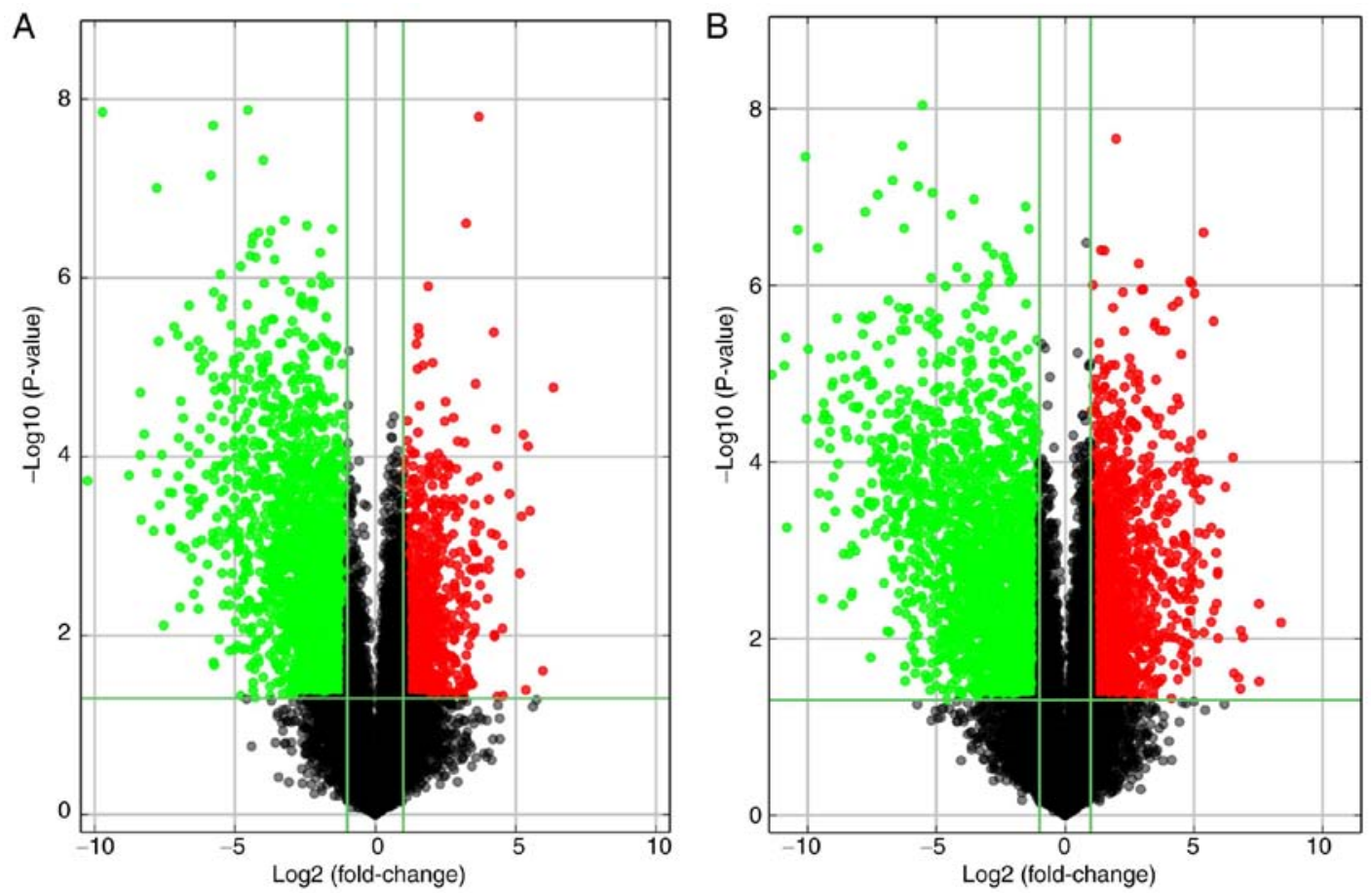

Figure 4. Volcano plot filtering was performed to identify (A) long non-coding RNAs and (B) mRNAs with statistically significant differences in expression. Vertical green lines correspond to 2.0 -fold upregulation and 2.0-fold downregulation of expression, and horizontal green lines indicate $\mathrm{P}=0.05$. Thus, the red and green points in the plot indicate $>2.0$-fold upregulation and downregulation of expression with statistical significance.

A

Systemic lupus erythematosus - Homo sapiens (human)

Alcoholism - Homo sapiens (human)

Viral carcinogenesis - Homo sapiens (human)

Cell cycle - Homo sapiens (human)

Osteoclast differentiation - Homo sapiens (human)

Natural killer cell mediated cytotoxicity - Homo sapiens (human)

Staphylococcus aureus infection - Homo sapiens (human)

Antigen processing and presentation - Homo sapiens (human)

Graft-versus-host disease - Homo sapiens (human)

HTLV-I infection - Homo sapiens (human)

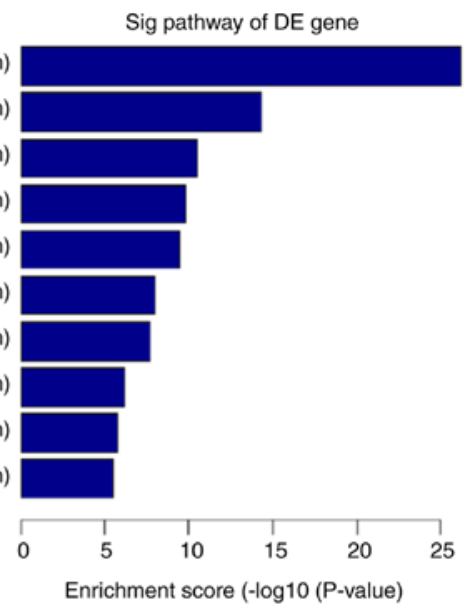

B

Sig pathway of DE gene

Drug metabolism-cytochrome P450 - Homo sapiens (human)

cGMP-PKG signaling pathway - Homo sapiens (human)

Chemical carcinogenesis - Homo sapiens (human)

Metabolism of xenobiotics by cytochrome P450 - Homo sapiens (human)

CAMP signaling pathway - Homo sapiens (human)

Bile secretion - Homo sapiens (human)

Calcium signaling pathway - Homo sapiens (human)

Circadian entrainment - Homo sapiens (human)

Vascular smooth muscle contraction - Homo sapiens (human)

Regulation of lipolysis in adipocytes - Homo sapiens (human)

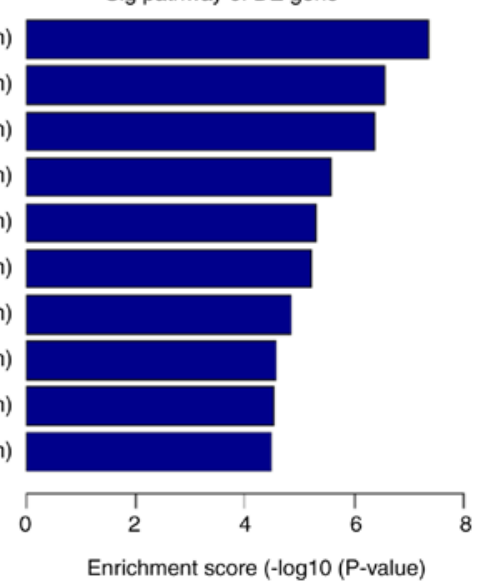

Figure 5. Pathway analysis report. The top 10 significant pathways of (A) upregulated and (B) downregulated genes in high-grade ovarian serous cancer. DE, differentially expressed. 
A

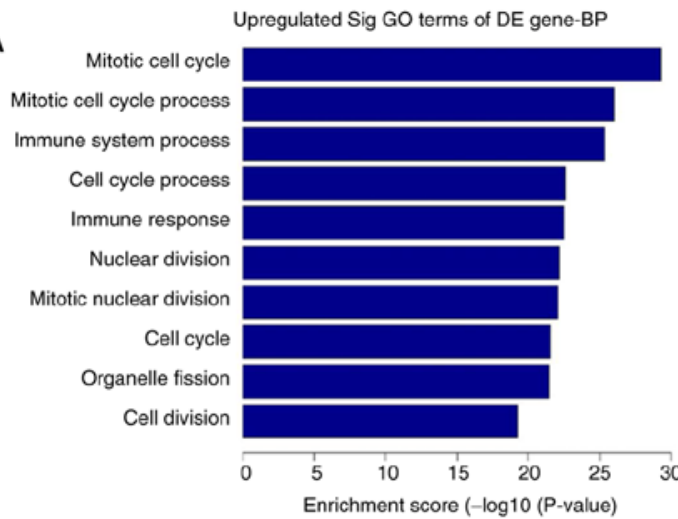

C

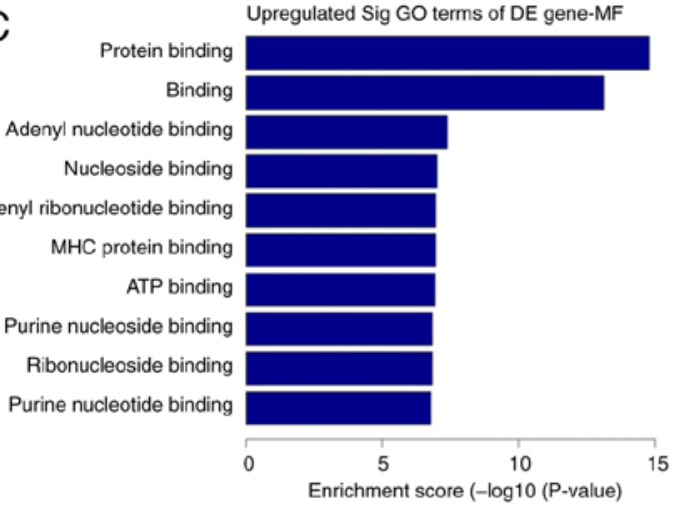

$E$

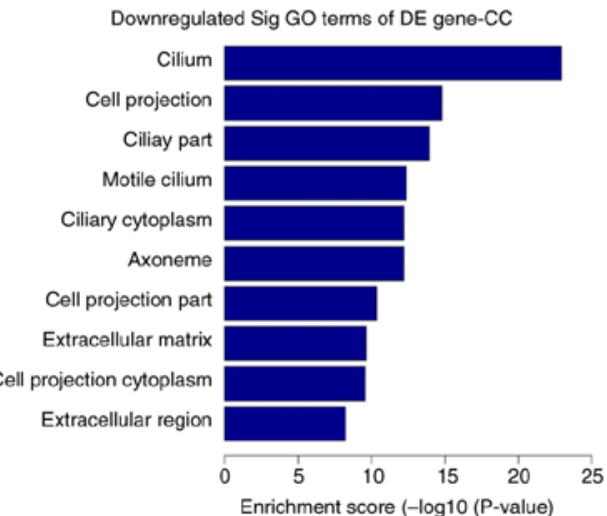

B

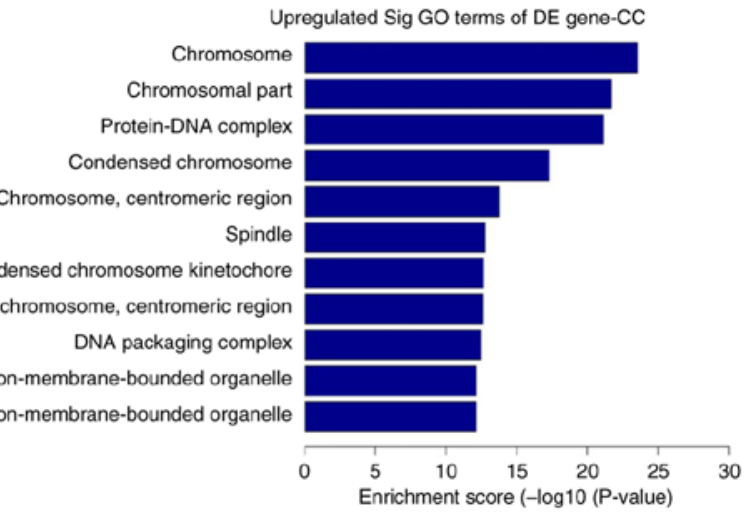

D

Downregulated Sig GO terms of DE gene-BP

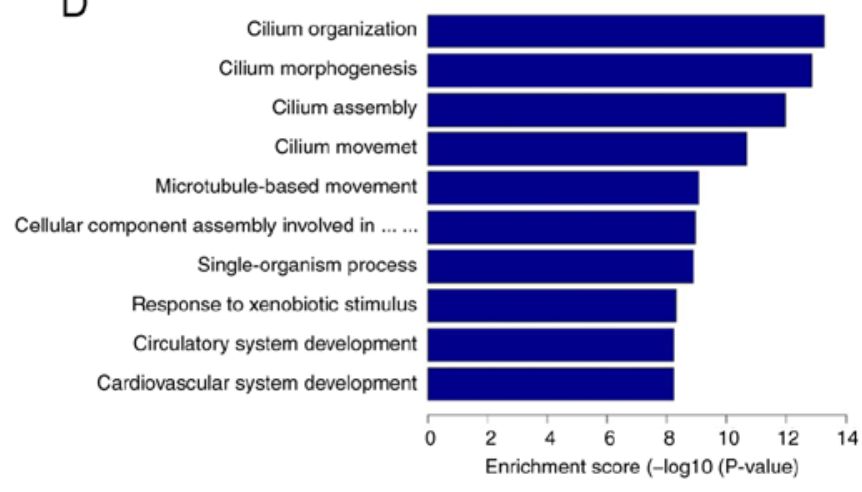

$\mathrm{F}$

Downregulated Sig GO terms of DE gene-MF

Sequence-spe

Direct ligand regulated sequence-specific DNA . Ligand-activated sequence-speific DNA binding RNA

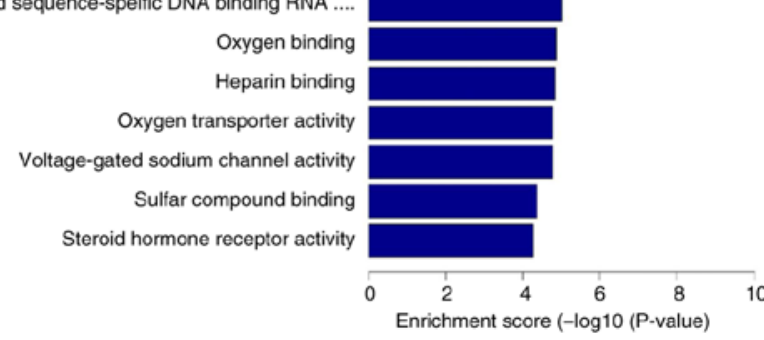

Figure 6. GO analysis report. The GO categories cover three domains: BP, CC and MF. The top 10 upregulated GO functions of the (A) BP, (B) CC and (C) MF domains. The top 10 downregulated GO functions of the (D) BP, (E) CC and (F) MF domains. GO, gene ontology; BP, biological process; CC, cellular component; MF, molecular function; DE, differentially expressed.

integrated to infer the function of the lncRNAs. The results revealed that 315 antisense lncRNAs and associated mRNAs were abnormally expressed (fold change, $\geq 2.0 ; \mathrm{P}<0.05$ ): 51 of the lncRNA-mRNA pairs were regulated in the up-up direction, 200 pairs were regulated in the down-down direction, 30 pairs were regulated in the up-down direction, and 34 pairs were regulated in the down-up direction. A total of 10 differentially expressed antisense lncRNAs and associated mRNAs are presented in Table V. In addition, long intergenic non-coding RNAs (lincRNAs) are of particular interest to the present study as they may be a novel factor associated with cancer progression (31). Statistical analysis of differentially expressed lincRNAs and their nearby mRNAs (distance $<300 \mathrm{~kb}$ ) was conducted. The results revealed that 1,807 lincRNAs and nearby mRNAs were abnormally expressed (fold change, $\geq 2.0 ; \mathrm{P}<0.05$ ): 475 of the lincRNA-mRNA pairs were regulated in the up-up direction, 738 pairs were regulated in the down-down direction, 264 pairs were regulated in the up-down direction and 330 pairs were regulated in the down-up direction. A total of 10 differentially expressed lincRNAs and nearby mRNAs are presented in Table VI.

Validation of microarray data with $R T-q P C R$. To validate the microarray consistency, RT-qPCR was performed. A total of 5 abnormally expressed lncRNAs (GTSE1-AS1, FAS-AS1, AK130076, RP11-199F11.2 and AC093818.1) and their associated mRNAs [G2 and S-phase expressed 1 (GTSE1), Fas surface cell death receptor $(F A S)$, phosphatase and tensin homolog (PTEN), tumor protein p53 (TP53) and pyruvate dehydrogenase kinase $1(P D K 1)$ ] were selected, and their expression was 

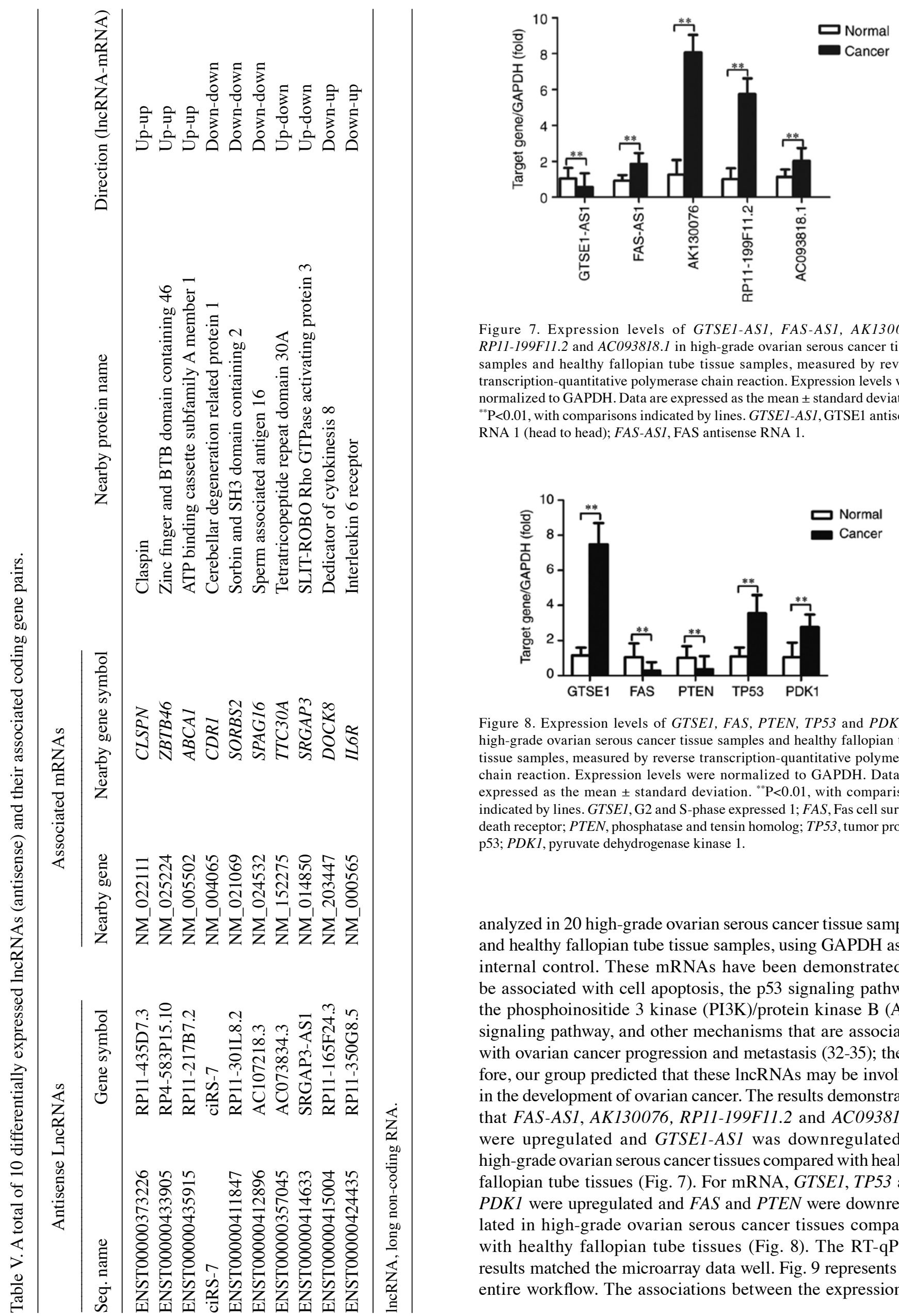

Figure 7. Expression levels of GTSE1-AS1, FAS-AS1, AK130076, RP11-199F11.2 and AC093818.1 in high-grade ovarian serous cancer tissue samples and healthy fallopian tube tissue samples, measured by reverse transcription-quantitative polymerase chain reaction. Expression levels were normalized to GAPDH. Data are expressed as the mean \pm standard deviation. ${ }^{* *} \mathrm{P}<0.01$, with comparisons indicated by lines. GTSE1-AS1, GTSE1 antisense RNA 1 (head to head); FAS-AS1, FAS antisense RNA 1.

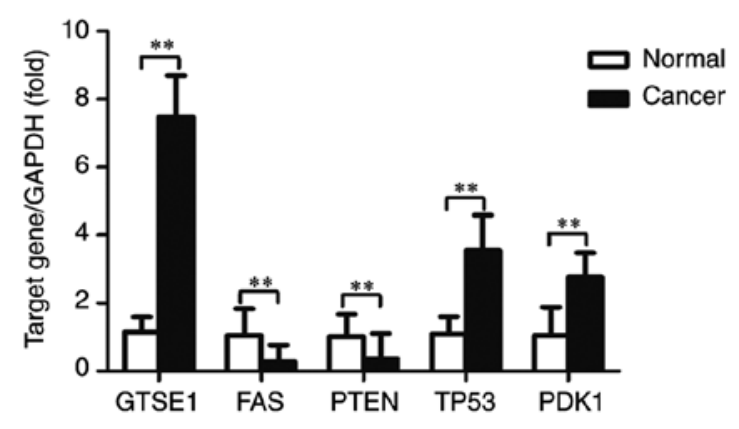

Figure 8. Expression levels of GTSE1, FAS, PTEN, TP53 and PDK1 in high-grade ovarian serous cancer tissue samples and healthy fallopian tube tissue samples, measured by reverse transcription-quantitative polymerase chain reaction. Expression levels were normalized to GAPDH. Data are expressed as the mean \pm standard deviation. ${ }^{* *} \mathrm{P}<0.01$, with comparisons indicated by lines. GTSE1, G2 and S-phase expressed 1; FAS, Fas cell surface death receptor; PTEN, phosphatase and tensin homolog; TP53, tumor protein p53; PDK1, pyruvate dehydrogenase kinase 1.

analyzed in 20 high-grade ovarian serous cancer tissue samples and healthy fallopian tube tissue samples, using GAPDH as an internal control. These mRNAs have been demonstrated to be associated with cell apoptosis, the p53 signaling pathway, the phosphoinositide 3 kinase (PI3K)/protein kinase B (Akt) signaling pathway, and other mechanisms that are associated with ovarian cancer progression and metastasis (32-35); therefore, our group predicted that these IncRNAs may be involved in the development of ovarian cancer. The results demonstrated that FAS-AS1, AK130076, RP11-199F11.2 and AC093818.1 were upregulated and GTSE1-AS1 was downregulated in high-grade ovarian serous cancer tissues compared with healthy fallopian tube tissues (Fig. 7). For mRNA, GTSE1, TP53 and $P D K 1$ were upregulated and FAS and PTEN were downregulated in high-grade ovarian serous cancer tissues compared with healthy fallopian tube tissues (Fig. 8). The RT-qPCR results matched the microarray data well. Fig. 9 represents the entire workflow. The associations between the expression of 
Table VI. A total of 10 cases of differentially expressed long non-coding RNAs (lincRNAs) and nearby coding gene pairs (distance $<300 \mathrm{~kb}$ ).

\begin{tabular}{|c|c|c|c|c|c|}
\hline & & Nearby & mRNAs & & \\
\hline & & & Nearby gene & & Direction \\
\hline Seq. name & Gene symbol & Nearby gene & symbol & Nearby protein name & (lncRNA-mRNA) \\
\hline ENST00000412295 & CTC-338M12.9 & NM_033549 & TRIM41 & Tripartite motif containing 41 & Up-up \\
\hline ENST00000412362 & $R P 11-236 B 18.2$ & NM_014391 & ANKRDI & $\begin{array}{l}\text { Ankyrin repeat domain } 1 \\
\text { (cardiac muscle) }\end{array}$ & Up-up \\
\hline ENST00000412427 & RP11-380J14.1 & NM_022089 & ATP13A2 & ATPase type $13 \mathrm{~A} 2$ & Up-up \\
\hline AF070541 & AF070541 & NM_030632 & $A S X L 3$ & $\begin{array}{l}\text { Additional sex combs like } 3 \text {, } \\
\text { transcriptional regulator }\end{array}$ & Down-down \\
\hline AF339807 & AF339807 & NM_015567 & SLITRK5 & $\begin{array}{l}\text { SLIT and NTRK like family } \\
\text { member } 5\end{array}$ & Down-down \\
\hline AK023372 & AK023372 & NM_000574 & $C D 55$ & $\begin{array}{l}\text { CD55 molecule (Cromer } \\
\text { blood group) }\end{array}$ & Down-down \\
\hline ENST00000413304 & АС098872.3 & NM_004657 & $S D P R$ & Serum deprivation response & Dp-down \\
\hline ENST00000417932 & RP11-10J5.1 & NM_022121 & PERP & PERP, TP53 apoptosis effector & Up-down \\
\hline AK055324 & AK055324 & NM_005184 & CALM3 & $\begin{array}{l}\text { Calmodulin } 3 \text { (phosphorylase } \\
\text { kinase, delta) }\end{array}$ & Down-up \\
\hline AL049990 & AL049990 & NM_024873 & TNIP3 & TNFAIP3 interacting protein 3 & Down-up \\
\hline
\end{tabular}

LincRNA, long intergenic non-coding RNA.

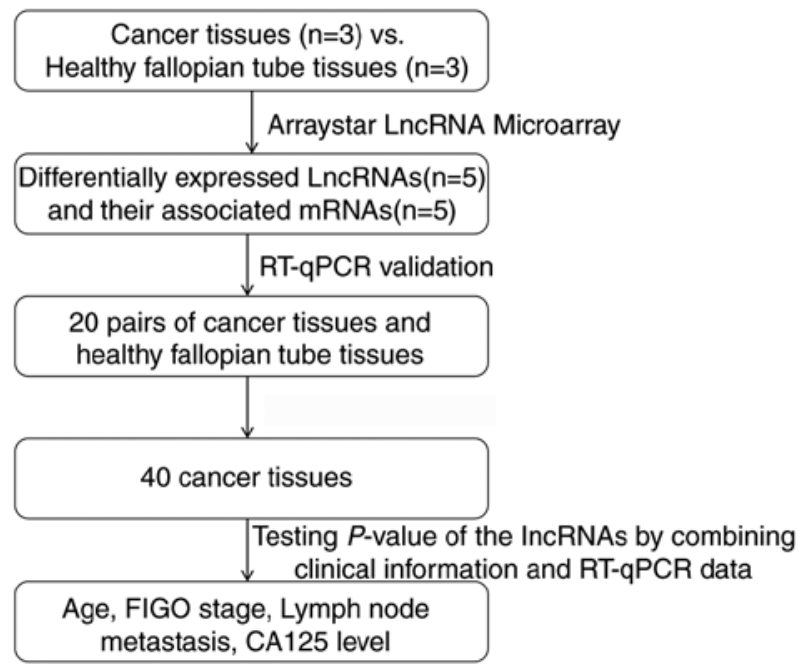

Figure 9. The entire workflow of the present study. RT-qPCR, reverse transcription-quantitative polymerase chain reaction; FIGO, International Federation of Gynecology and Obstetrics; lncRNA, long non-coding RNA; CA125, cancer antigen 125.

the 5 lncRNAs and clinicopathological parameters in patients with high-grade ovarian serous cancer patients are presented in Table VII. The microarray results of the selected lncRNAs are presented in Table VIII. These lncRNAs were significantly associated with International Federation of Gynecology and Obstetrics (FIGO) stage (36) and lymph node metastases in ovarian cancer. These results suggested that these differentially expressed lncRNAs may be associated with ovarian carcinogenesis and tumor progression.

\section{Discussion}

Treatment of high-grade ovarian serous cancer remains a serious challenge and the disease represents a global health problem for women, with a 5-year mortality rate of $>70 \%$ and a high incidence of metastasis (37). Although the molecular mechanisms underlying high-grade ovarian serous cancer have been investigated, the exact pathogenesis of this disease remains unclear. Therefore, investigation of molecular markers and effective therapeutic strategies targeting high-grade ovarian serous cancer are of great value. At present, an increasing number of studies have indicated that lncRNAs are involved in the regulation of a wide variety of biological processes (38). However, the function that lncRNAs serve in cancer is of particular interest. An increasing number of studies have reported that several types of tumor are associated with differentially expressed IncRNAs, which are involved in occurrence, development, invasion, metastasis, apoptosis and drug resistance, via a series of complicated mechanisms $(39,40)$. For instance, lncRNA $U C A l$ was detected in bladder cancer tissues and cell lines, and the expression levels of UCAl were significantly higher than that in a control group. Overexpression of $U C A 1$ increases the proliferation, invasion, and metastasis of bladder cancer cells (41). Hou et al (14) discovered that long intergenic non protein-coding RNA, regulator of reprogramming ( $L I N C-R O R)$ was upregulated in breast tumor samples, and ectopic overexpression of $L I N C$-ROR increased breast cancer cell migration and invasion. Furthermore, LINC-ROR functioned as a competing endogenous RNA to microRNA-205 and induced epithelial-to-mesenchymal transition (14). In addition, dysregulation of lncRNAs, including 
Table VII. Associations between long non-coding RNA expression and clinicopathological parameters in 40 patients with high-grade ovarian serous cancer.

\begin{tabular}{|c|c|c|c|c|c|c|c|c|}
\hline \multirow[b]{2}{*}{ Parameter } & \multicolumn{2}{|c|}{ Age (years) } & \multicolumn{2}{|c|}{ FIGO stage } & \multicolumn{2}{|c|}{$\begin{array}{l}\text { Lymph node } \\
\text { metastasis }\end{array}$} & \multicolumn{2}{|c|}{$\begin{array}{l}\text { CA125 level } \\
(\mathrm{U} / \mathrm{ml})\end{array}$} \\
\hline & $<50$ & $\geq 50$ & I-II & III-IV & Negative & Positive & $<600$ & $\geq 600$ \\
\hline \multicolumn{9}{|l|}{ GTSE1-AS1 } \\
\hline High no. cases & 6 & 8 & 5 & 4 & 6 & 4 & 10 & 6 \\
\hline Low no. cases & 10 & 16 & 16 & 15 & 17 & 13 & 15 & 9 \\
\hline P-value & 0.548 & & $<0.01$ & & $<0.01$ & & 0.432 & \\
\hline \multicolumn{9}{|l|}{$F A S-A S 1$} \\
\hline High no. cases & 9 & 15 & 17 & 14 & 16 & 12 & 17 & 8 \\
\hline Low no. cases & 7 & 9 & 4 & 5 & 7 & 5 & 8 & 7 \\
\hline P-value & 0.433 & & $<0.01$ & & $<0.01$ & & 0.694 & \\
\hline \multicolumn{9}{|l|}{ AK130076 } \\
\hline High no. cases & 10 & 16 & 18 & 15 & 18 & 12 & 17 & 10 \\
\hline Low no. cases & 6 & 8 & 3 & 4 & 5 & 5 & 8 & 5 \\
\hline P-value & 0.249 & & $<0.01$ & & $<0.01$ & & 0.167 & \\
\hline \multicolumn{9}{|l|}{$R P 11-199 F 11.2$} \\
\hline High no. cases & 10 & 15 & 16 & 16 & 20 & 11 & 14 & 9 \\
\hline Low no. cases & 6 & 9 & 5 & 3 & 3 & 6 & 11 & 6 \\
\hline P-value & 0.726 & & $<0.01$ & & $<0.01$ & & 0.259 & \\
\hline \multicolumn{9}{|l|}{ АС093818.1 } \\
\hline High no. cases & 11 & 14 & 15 & 14 & 17 & 14 & 16 & 8 \\
\hline Low no. cases & 5 & 10 & 6 & 5 & 6 & 3 & 9 & 7 \\
\hline P-value & 0.673 & & $<0.01$ & & $<0.01$ & & 0.464 & \\
\hline
\end{tabular}

Table VIII. Microarray results of the selected five long non-coding RNAs.

A, Downregulated

\begin{tabular}{lccccc}
\hline Seq. name & Gene symbol & $\begin{array}{c}\text { Fold } \\
\text { change }\end{array}$ & Chromosome & $\begin{array}{c}\text { Associated } \\
\text { gene name }\end{array}$ & Associated protein name \\
\hline NR_024009 & GTSE1-AS1 & 3.11 & chr22 & GTSE1 & G2 and S phase-expressed protein 1 \\
\hline
\end{tabular}

B, Upregulated

\begin{tabular}{llcccl}
\hline Seq. name & Gene symbol & $\begin{array}{c}\text { Fold } \\
\text { change }\end{array}$ & Chromosome & $\begin{array}{c}\text { Associated } \\
\text { gene name }\end{array}$ & \multicolumn{1}{c}{ Associated protein name } \\
\hline NR_028371 & FAS-AS1 & 2.01 & chr10 & FAS & $\begin{array}{l}\text { Tumor necrosis factor receptor superfamily } \\
\text { member 6 isoform 1 precursor }\end{array}$ \\
uc001kfc.1 & AK130076 & 6.08 & chr10 & PTEN & $\begin{array}{l}\text { Phosphatidylinositol 3,4,5-trisphosphate } \\
\text { 3-phosphatase and dual-specificity protein } \\
\text { Phosphatase PTEN }\end{array}$ \\
ENST00000571370 & $\begin{array}{l}\text { RP11-199F11.2 } \\
\text { ENST00000436922 }\end{array}$ & 5.87 & chr17 & TP53 & $\begin{array}{l}\text { Cellular tumor antigen p53 isoform a } \\
\text { Pyruvate dehydrogenase kinase, isozyme 1 }\end{array}$ \\
\hline
\end{tabular}


HOTAIR, metastasis associated lung adenocarcinoma transcript 1, antisense non-coding RNA in the INK4 locus, growth arrest-specific 5, cervical carcinoma expressed PCNA regulatory lncRNA, H19, imprinted maternally expressed transcript (non-protein coding), and lncRNA-activated by TGF $\beta$, has been demonstrated to exacerbate several human cancers, including small-cell lung cancer (12), prostate cancer (42), gastric cancer (15), colorectal cancer (43), cervical cancer (44), liver cancer (45) and pancreatic cancer (46). Therefore, lncRNAs represent potential indicators of tumor prognosis and diagnosis.

Usually, searching for differentially expressed lncRNAs with high-throughput microarray technologies in cell lines and tissues is the first step in the study of genes. Zhou et al (47) investigated differences in IncRNA and mRNA expression profiles between hypopharyngeal squamous cell carcinoma tissues and adjacent non-tumor tissues by microarray analysis, and identified a series of significantly dysregulated lncRNAs and mRNAs. These results laid the foundation for their following research. Similar studies have been carried out in pancreatic cancer, endometrial cancer and nasopharyngeal carcinoma (48-50).

In the present study, three pairs of high-grade ovarian serous cancer tissue samples and healthy fallopian tube tissue samples were used to investigate the differences in lncRNA and mRNA expression profiles through microarray analysis. The results revealed that the expression profiles of lncRNAs and mRNAs in high-grade ovarian serous cancer tissues were significantly altered. In addition, compared with the number of upregulated genes, the number of downregulated genes was larger, indicating that this may influence the occurrence and development of high-grade ovarian serous cancer. These differentially expressed genes were subsequently organized into hierarchical categories based on heat maps of hierarchical clustering, and the differences in lncRNA and mRNA expression between the two groups were analyzed by scatter plot and volcano plot filtering. Furthermore, GO and pathway analysis were performed to obtain information on the biological functions and potential mechanisms underlying the action of these differentially expressed lncRNAs. However, more detailed research should be performed to investigate the specific mechanisms existing between these pathways, networks and genes.

Antisense lncRNA has been the subject of intense research among lncRNAs (51). In total, $>30 \%$ of annotated human transcripts have corresponding antisense lncRNAs. These antisense lncRNAs regulate the corresponding sense lncRNAs at transcription or post transcription level through a variety of mechanisms, and serve an important biological function. In addition, lincRNAs are a subject of particular interest to the present study (52). Multiple studies have demonstrated that a common and important function of lncRNAs is to alter the expression of nearby coding genes by affecting their transcription (53-55). Therefore, in the present study, differentially expressed antisense lncRNAs, lincRNAs, and their associated mRNAs were integrated in order to infer the function of IncRNAs in IncRNA-mRNA coexpression, which may predict the target genes of lncRNAs. Subgroup analysis results identified 315 abnormally expressed antisense lncRNAs and associated mRNAs, as well as 1807 abnormally expressed lincRNAs and nearby mRNAs. However, the function of this lncRNA-mRNA coexpression requires further research.
To confirm the microarray consistency, 5 differentially expressed 1ncRNAs (GTSE1-AS1, FAS-AS1, AK130076, $R P 11-199 F 11.2$ and $A C 093818.1)$ and their associated mRNAs (GTSE1, FAS, PTEN, TP53 and PDK1) were selected to verify expression consistency by RT-qPCR. FAS has been reported to be associated with ovarian cancer cell apoptosis (32). PTEN serves an important biological function in ovarian cancer cell growth, proliferation, and migration (34). TP53 is a common tumor suppressor gene, which influences ovarian cancer cell proliferation and cell cycle through the p53 signaling pathway (33). PDK1 is involved in the development and drug resistance mechanisms of ovarian cancer by regulating the PI3K/Akt signaling pathway (35). The present study revealed that GTSE1, FAS, PTEN, TP53, and $P D K 1$ are the associated mRNAs of GTSE1-AS1, FAS-AS1, $A K 130076, R P 11-199 F 11.2$ and AC093818.1, suggesting that these lncRNAs may serve a role in the development of ovarian cancer. In particular, the expression of 4 lncRNAs (FAS-AS1, AK130076, RP11-199F11.2 and AC093818.1) was significantly increased in high-grade ovarian serous cancer tissues compared with healthy fallopian tube tissues, while the expression of GTSE1-AS1 was significantly lower. The expression of 3 associated mRNAs (GTSE1, TP53 and PDK1) was significantly increased in high-grade ovarian serous cancer tissues; that of FAS and PTEN was significantly decreased compared with normal tissues. These results are consistent with the microarray data and reflect the variable expression of lncRNAs and mRNAs in different tissues. Furthermore, the expression of the selected IncRNAs was significantly associated with ovarian cancer FIGO stages and lymph node metastases in 40 patients with high-grade ovarian serous cancer. These results provide more evidence that these differentially expressed lncRNAs may be associated with ovarian carcinogenesis and tumor progression. Although the biological functions of a large number of genes remain unclear, the data from the present study may be useful for further studies on the pathogenesis and underlying molecular mechanisms of high-grade ovarian serous cancer. Multiple further studies are necessary to strengthen the association between lncRNAs and high-grade ovarian serous cancer. In consequent work, our group will further explore gene expression and clinical data in high-grade ovarian serous cancer according to The Cancer Genome Atlas and Gene Expression Omnibus databases, and analyze the associations with the prognosis of patients with high-grade ovarian serous cancer. Further experiments, including immunohistochemistry, western blot analysis and other in vivo and in vitro experiments will be performed to identify the specific molecular mechanisms and biochemical functions between lncRNAs and high-grade ovarian serous cancer.

In conclusion, to the best of our knowledge, the present study was the first to examine differences in lncRNA and mRNA expression profiles between high-grade ovarian serous cancer tissues and healthy fallopian tube tissues using microarray analysis. According to the present study, 4,289 lncRNAs and 4,246 mRNAs were differentially expressed in high-grade ovarian serous cancer tissues, and may serve a key function in the occurrence and development of high-grade ovarian serous cancer. Furthermore, bioinformatics analyses were applied to determine the potential functions of these abnormally 
expressed genes. In the near future, our group will conduct more detailed research on several lncRNAs, and identify their specific molecular mechanisms and biochemical functions for the purpose of providing effective methods for the diagnosis and therapy of high-grade ovarian serous cancer.

\section{Acknowledgements}

Not applicable.

\section{Funding}

This study was supported by the Science and Technology Support Program of Qingdao, Shandong, China [grant no. 2012-1-3-2-(9)-nsh].

\section{Availability of data and materials}

The datasets used and analyzed during the current study are available from the corresponding author on reasonable request.

\section{Authors' contributions}

YL and HJ conceived and designed the study. ZC and $\mathrm{YH}$ collected the specimens. YL, HJ, XW and LW performed the experiments. YL and HJ wrote the paper. ZC, YH, XW and LW reviewed and edited the manuscript. All authors read and approved the final manuscript.

\section{Ethics approval and consent to participate}

All subjects provided signed statements of written informed consent. All experimental procedures were approved by the Institutional Review Board of the Ethics Board of the Affiliated Hospital of Qingdao University (Qingdao, China).

\section{Consent for publication}

All patients provided written informed consent for the publication of their data.

\section{Competing interests}

The authors declare that they have no competing interests.

\section{References}

1. Bast RC Jr, Hennessy B and Mills GB: The biology of ovarian cancer: New opportunities for translation. Nat Rev Cancer 9: 415-428, 2009.

2. Siegel R, Naishadham D and Jemal A: Cancer statistics, 2013. CA Cancer J Clin 63: 11-30, 2013.

3. Yiwei T, Hua H, Hui G, Mao M and Xiang L: HOTAIR interacting with MAPK1 regulates ovarian cancer skov3 cell proliferation, migration, and invasion. Med Sci Monit 21: $1856-1863,2015$

4. ENCODEProject Consortium, Birney E, Stamatoyannopoulos JA, Dutta A, Guigó R, Gingeras TR, Margulies EH, Weng Z Snyder M, Dermitzakis ET, et al: Identification and analysis of functional elements in 1\% of the human genome by the ENCODE pilot project. Nature 447: 799-816, 2007.

5. Nagano $T$ and Fraser P: No-nonsense functions for long noncoding RNAs. Cell 145: 178-181, 2011.
6. Yang Q, Xu E, Dai J, Liu B, Han Z, Wu J, Zhang S, Peng B, Zhang Y and Jiang Y: A novel long noncoding RNA AK001796 acts as an oncogene and is involved in cell growth inhibition by resveratrol in lung cancer. Toxicol Appl Pharmacol 285: 79-88, 2015.

7. Gibb EA, Brown CJ and Lam WL: The functional role of long non-coding RNA in human carcinomas. Mol Cancer 10: 38, 2011.

8. Zhang H, Chen Z, Wang X, Huang Z, He Z and Chen Y: Long non-coding RNA: A new player in cancer. J Hematol Oncol 6 : 37, 2013.

9. Tang SC and Chen YC: Novel therapeutic targets for pancreatic cancer. World J Gastroenterol 20: 10825-10844, 2014.

10. Zeng Z, Bo H, Gong Z, Lian Y, Li X, Li X, Zhang W, Deng H, Zhou M, Peng S, et al: AFAP1-AS1, a long noncoding RNA upregulated in lung cancer and promotes invasion and metastasis. Tumour Biol 37: 729-737, 2016.

11. Qiu JJ, Wang Y, Ding JX, Jin HY, Yang G and Hua KQ: The long non-coding RNA HOTAIR promotes the proliferation of serous ovarian cancer cells through the regulation of cell cycle arrest and apoptosis. Exp Cell Res 333: 238-248, 2015.

12. Ono H, Motoi N, Nagano H, Miyauchi E, Ushijima M, Matsuura M, Okumura S, Nishio M, Hirose T, Inase N and Ishikawa Y: Long noncoding RNA HOTAIR is relevant to cellular proliferation, invasiveness, and clinical relapse in small-cell lung cancer. Cancer Med 3: 632-642, 2014.

13. Han Y, Liu Y, Zhang H, Wang T, Diao R, Jiang Z, Gui Y and Cai Z: Hsa-miR-125b suppresses bladder cancer development by down-regulating oncogene SIRT7 and oncogenic long noncoding RNA MALAT1. FEBS Lett 587: 3875-3882, 2013.

14. Hou P, Zhao Y, Li Z, Yao R, Ma M, Gao Y, Zhao L, Zhang Y, Huang $B$ and Lu J: LincRNA-ROR induces epithelial-to-mesenchymal transition and contributes to breast cancer tumorigenesis and metastasis. Cell Death Dis 5: e1287, 2014.

15. Zhang EB, Kong R, Yin DD, You LH, Sun M, Han L, Xu TP, Xia R, Yang JS, De W and Chen Jf: Long noncoding RNA ANRIL indicates a poor prognosis of gastric cancer and promotes tumor growth by epigenetically silencing of miR-99a/miR-449a. Oncotarget 5: 2276-2292, 2014

16. Xia T, Chen S, Jiang Z, Shao Y, Jiang X, Li P, Xiao B and Guo J: Long noncoding RNA FER1L4 suppresses cancer cell growth by acting as a competing endogenous RNA and regulating PTEN expression. Sci Rep 5: 13445, 2015.

17. Qiu JJ, Lin YY, Ye LC, Ding JX, Feng WW, Jin HY, Zhang Y, $\mathrm{Li} \mathrm{Q}$ and Hua KQ: Overexpression of long non-coding RNA HOTAIR predicts poor patient prognosis and promotes tumor metastasis in epithelial ovarian cancer. Gynecol Oncol 134: 121-128, 2014.

18. Richards EJ, Permuth-Wey J, Li Y, Chen YA, Coppola D, Reid BM, Lin HY, Teer JK, Berchuck A, Birrer MJ, et al: A functional variant in HOXA11-AS, a novel long non-coding RNA, inhibits the oncogenic phenotype of epithelial ovarian cancer. Oncotarget 6: 34745-34757, 2015.

19. Gao Y, Meng H, Liu S, Hu J, Zhang Y, Jiao T, Liu Y, Ou J, Wang D, Yao L, et al: LncRNA-HOST2 regulates cell biological behaviors in epithelial ovarian cancer through a mechanism involving microRNA let-7b. Hum Mol Genet 24: 841-852, 2015.

20. Li J, Zhou D, Wang Z, Tan L, Zhou Y, Li J and Sheng X: Reversal effect of 5-aza-2-deoxycytidine on the maternally expressed gene 3 promoter hypermethylation and its inhibitory effect on the proliferation of epithelial ovarian cancer cells. Zhonghua Zhong Liu Za Zhi 37: 324-329, 2015 (In Chinese).

21. Yang Y, Jiang Y, Wan Y, Zhang L, Qiu J, Zhou S and Cheng W: UCA1 functions as a competing endogenous RNA to suppress epithelial ovarian cancer metastasis. Tumour Biol 37: 10633-10641, 2016.

22. Ashburner M, Ball CA, Blake JA, Botstein D, Butler H, Cherry JM, Davis AP, Dolinski K, Dwight SS, Eppig JT, et al: Gene ontology: Tool for the unification of biology. The Gene Ontology Consortium. Nat Genet 25: 25-29, 2000.

23. The Gene Ontology Consortium. Expansion of the Gene Ontology knowledgebase and resources. Nucleic Acids Res 45(D1): D331-D338, 2017.

24. Livak KJ and Schmittgen TD: Analysis of relative gene expression data using real-time quantitative PCR and the 2(-Delta Delta C(T)) method. Methods 25: 402-408, 2001.

25. Kanehisa M and Goto S: KEGG: Kyoto encyclopedia of genes and genomes. Nucleic Acids Res 28: 27-30, 2000.

26. Darryl N: Biotech Software \& Internet Report 2: 117-120, 2004. 
27. Fabregat A, Jupe S, Matthews L, Sidiropoulos K, Gillespie M, Garapati P, Haw R, Jassal B, Korninger F, May B, et al: The reactome pathway knowledgebase. Nucleic Acids Res 46(D1): D649-D655, 2018

28. Milacic M, Haw R, Rothfels K, Wu G, Croft D, Hermjakob H, D'Eustachio P and Stein L: Annotating cancer variants and anti-cancer therapeutics in reactome. Cancers (Basel) 4: $1180-1211,2012$

29. Yang Y, Li H, Hou S, Hu B, Liu J and Wang J: The noncoding RNA expression profile and the effect of lncRNA AK126698 on cisplatin resistance in non-small-cell lung cancer cell. PLoS One 8: e65309, 2013.

30. Cao G, Zhang J, Wang M, Song X, Liu W, Mao C and Lv C: Differential expression of long non-coding RNAs in bleomycin-induced lung fibrosis. Int J Mol Med 32: 355-364, 2013.

31. Tsai MC, Spitale RC and Chang HY: Long intergenic noncoding RNAs: New links in cancer progression. Cancer Res 71: 3-7, 2011.

32. Cohen M, Pierredon S, Wuillemin C, Delie F and Petignat P: Acellular fraction of ovarian cancer ascites induce apoptosis by activating JNK and inducing BRCA1, Fas and FasL expression in ovarian cancer cells. Oncoscience 1: 262-271, 2014.

33. Hayano T, Yokota Y, Hosomichi K, Nakaoka H, Yoshihara K, Adachi S, Kashima K, Tsuda H, Moriya T, Tanaka K, et al Molecular characterization of an intact p53 pathway subtype in high-grade serous ovarian cancer. PLoS One 9: e114491, 2014.

34. Li J, Hu K, Gong G, Zhu D, Wang Y, Liu H and Wu X: Upregulation of MiR-205 transcriptionally suppresses SMAD4 and PTEN and contributes to human ovarian cancer progression. Sci Rep 7: 41330, 2017.

35. Bugide S, Gonugunta VK, Penugurti V, Malisetty VL, Vadlamudi RK and Manavathi B: HPIP promotes epithelial-mesenchymal transition and cisplatin resistance in ovarian cancer cells through PI3K/AKT pathway activation. Cell Oncol (Dordr) 40: 133-144, 2017.

36. Zeppernick F and Meinhold-Heerlein I: The new FIGO staging system for ovarian, fallopian tube, and primary peritoneal cancer Arch Gynecol Obstet 290: 839-842, 2014.

37. Jelovac D and Armstrong DK: Recent progress in the diagnosis and treatment of ovarian cancer. CA Cancer J Clin 61: 183-203, 2011.

38. Ji Q, Zhang L, Liu X, Zhou L, Wang W, Han Z, Sui H, Tang Y, Wang Y, Liu N, et al: Long non-coding RNA MALAT1 promotes tumour growth and metastasis in colorectal cancer through binding to SFPQ and releasing oncogene PTBP2 from SFPQ/PTBP2 complex. Br J Cancer 111: 736-748, 2014.

39. Shi Y, Liu Y, Wang J, Jie D, Yun T, Li W, Yan L, Wang K and Feng J: Downregulated long noncoding RNA BANCR promotes the proliferation of colorectal cancer cells via downregualtion of p21 expression. PLoS One 10: e0122679, 2015.

40. Xue M, Li X, Li Z and Chen W: Urothelial carcinoma associated 1 is a hypoxia-inducible factor-1alpha-targeted long noncoding RNA that enhances hypoxic bladder cancer cell proliferation, migration, and invasion. Tumour Biol 35: 6901-6912, 2014

41. Srivastava AK, Singh PK, Rath SK, Dalela D, Goel MM and Bhatt ML: Appraisal of diagnostic ability of UCA1 as a biomarker of carcinoma of the urinary bladder. Tumour Biol 35: $11435-11442,2014$

42. Wang F, Ren S, Chen R, Lu J, Shi X, Zhu Y, Zhang W, Jing T, Zhang C, Shen J, et al: Development and prospective multicenter evaluation of the long noncoding RNA MALAT-1 as a diagnostic urinary biomarker for prostate cancer. Oncotarget 5 : $11091-11102,2014$
43. Yin D, He X, Zhang E, Kong R, De W and Zhang Z: Long noncoding RNA GAS5 affects cell proliferation and predicts a poor prognosis in patients with colorectal cancer. Med Oncol 31: 253, 2014

44. Yang M, Zhai X, Xia B, Wang Y and Lou G: Long noncoding RNA CCHE1 promotes cervical cancer cell proliferation via upregulating PCNA. Tumour Biol 36: 7615-7622, 2015.

45. Li H, Li J, Jia S, Wu M, An J, Zheng Q, Zhang W and Lu D: miR675 upregulates long noncoding RNA H19 through activating EGR1 in human liver cancer. Oncotarget 6: 31958-31984, 2015.

46. Qu S, Yang X, Song W, Sun W, Li X, Wang J, Zhong Y, Shang R, Ruan B, Zhang Z, et al: Downregulation of lncRNA-ATB correlates with clinical progression and unfavorable prognosis in pancreatic cancer. Tumour Biol 37: 3933-3938, 2016.

47. Zhou J, Li W, Jin T, Xiang X, Li M, Wang J, Li G, Pan X and Lei D: Gene microarray analysis of lncRNA and mRNA expression profiles in patients with hypopharyngeal squamous cell carcinoma. Int J Clin Exp Med 8: 4862-4882, 2015.

48. Zhou M, Ye Z, Gu Y, Tian B, Wu B and Li J: Genomic analysis of drug resistant pancreatic cancer cell line by combining long non-coding RNA and mRNA expression profling. Int J Clin Exp Pathol 8: 38-52, 2015.

49. Yang L, Zhang J, Jiang A, Liu Q, Li C, Yang C and Xiu J: Expression profile of long non-coding RNAs is altered in endometrial cancer. Int J Clin Exp Med 8: 5010-5021, 2015.

50. Yang QQ and Deng YF: Genome-wide analysis of long non-coding RNA in primary nasopharyngeal carcinoma by microarray. Histopathology 66: 1022-1030, 2015

51. Xie M, Sun M, Zhu YN, Xia R, Liu YW, Ding J, Ma HW, He XZ, Zhang ZH, Liu ZJ, et al: Long noncoding RNA HOXA-AS2 promotes gastric cancer proliferation by epigenetically silencing P21/PLK3/DDIT3 expression. Oncotarget 6: 33587-33601, 2015.

52. Zhou X, Gao Q, Wang J, Zhang X, Liu K and Duan Z: Linc-RNA-RoR acts as a 'sponge' against mediation of the differentiation of endometrial cancer stem cells by microRNA-145. Gynecol Oncol 133: 333-339, 2014.

53. Khalil AM, Guttman M, Huarte M, Garber M, Raj A, Rivea Morales D, Thomas K, Presser A, Bernstein BE, van Oudenaarden A, et al: Many human large intergenic noncoding RNAs associate with chromatin-modifying complexes and affect gene expression. Proc Natl Acad Sci USA 106: 11667-11672, 2009.

54. Mattick JS and Gagen MJ: The evolution of controlled multitasked gene networks: The role of introns and other noncoding RNAs in the development of complex organisms. Mol Biol Evol 18: 1611-1630, 2001.

55. Popadin K, Gutierrez-Arcelus M, Dermitzakis ET and Antonarakis SE: Genetic and epigenetic regulation of human lincRNA gene expression. Am J Hum Genet 93: 1015-1026, 2013.

This work is licensed under a Creative Commons Attribution-NonCommercial-NoDerivatives 4.0 International (CC BY-NC-ND 4.0) License. 